\title{
CONTRA O KAROSHI E A BIRÔLA: ANÁLISE DA EFETIVIDADE DOS MECANISMOS DE PROTEÇÃO CONTRA O EXCESSO DE HORAS DE TRABALHO NO BRASIL COMO FORMA DE GARANTIA DO DIREITO FUNDAMENTAL À SAÚDE ${ }^{1}$
}

\author{
AGAINST KAROSHI AND BIRÔLA: ANALYSIS OF THE EFFECTIVENESS OF PROTECTIVE \\ MECHANISMS AGAINST EXCESS OF WORKING HOURS IN BRAZIL AS A GUARANTEE FOR THE \\ FUNDAMENTAL RIGHT TO HEALTH
}

Renato Braz Mehanna Khamis ${ }^{2}$ Alan Martinez Kozyreff 3

\begin{abstract}
Resumo: O presente trabalho tem como objetivo analisar o excesso de jornada de trabalho no Brasil, bem como a efetividade dos mecanismos jurídicos disponíveis para a proteção da saúde do trabalhador submetido a estas condições. Visando atingir o objetivo proposto serão apresentados os males à saúde do trabalhador quando exposto a um grande número de horas de trabalho, tomando inicialmente como parâmetro comparativo os casos de karoshi e karojisatsu - morte por exaustão decorrente das horas de trabalho no Japão e em outros países asiáticos, como China, Coréia do Sul e Taiwan. Além disso serão apresentados dados estatísticos e casos concretos de trabalho excessivo no Brasil - inclusive com resultado morte (birôla) - e, ao final, serão analisados os mecanismos existentes para a proteção da saúde do trabalhador contra o excesso de jornada, de modo a permitir uma análise crítica sobre a sua eficácia ante os casos concretos. Para tanto, foi empregado o método histórico-crítico em pesquisa num primeiro momento quantitativa e descritiva - vez que à partir dos dados quantitativos disponíveis descreve o problema no Japão e no Brasil - e, num segundo, qualitativa e aplicada - pois analisa qualitativamente os mecanismos existentes e apresenta resultados orientados à sua implementação nos casos concretos. Adotou-se os procedimentos bibliográfico e normativo, pois amparado por referências normativas e teóricas publicadas em meio escrito e eletrônico.
\end{abstract}

Palavras-chave: efetividade; proteção; excesso; jornada de trabalho; direito à saúde.

\begin{abstract}
The present study aims to analyze the excess of working hours in Brazil, as well as the effectiveness of the legal mechanisms available for the protection of the health of the worker subjected to these conditions. Aiming at reaching the proposed goal, the evils will be presented to the health of the worker when exposed to a large number of working hours, initially taking as a comparative parameter the cases of karoshi and karojisatsu - death due to exhaustion due to working hours in Japan and in other countries Asian countries. In addition, statistical data and concrete cases of excessive work in Brazil - including death (birôla) - will be presented and, finally, the existing mechanisms for the protection of the worker's health against overwork will be analyzed, in order to allow a critical analysis of their effectiveness in concrete cases. In order to do so, the historical-critical research method was used in a first quantitative and descriptive way - instead, from the available quantitative data, it describes the problem in Japan and Brazil - and, in a second, qualitative and applied one - because it qualitatively analyzes the mechanisms and results oriented towards their

\footnotetext{
1 O presente artigo é resultado de projeto de pesquisa realizado no âmbito do Grupo de Pesquisa (CNPQ) "A eficácia dos direitos fundamentais e a efetividade do direito fundamental à saúde", vinculando ao Programa de Mestrado em Direito da Saúde da Universidade Santa Cecília - UNISANTA.

2 Doutor e Mestre em Direito do Estado pela Pontifícia Universidade Católica de São Paulo; Professor Permanente do Programa de Pós-graduação Stricto Sensu em Direito à Saúde da Universidade Santa Cecília; https://orcid.org/0000-00018306-9174; renato@mehanna.adv.br

3 Mestre em Direito da Saúde pela Universidade Santa Cecília; doutorando em Ciências Farmacêuticas pela Universidade de Sorocaba; Professor do Curso de graduação em Direito da Universidade de Sorocaba; https://orcid.org/0000-0001-85665121; alankozyreff@gmail.com
} 
implementation in concrete cases. The bibliographic and normative procedures were adopted, as supported by normative and theoretical references published in written and electronic media.

Keywords: effectiveness; protection; excess; working day; right to health.

Recebido em 13 de outubro de 2018 Avaliado em 3 de março de 2021(Avaliador A) Avaliado em 11 de setembro de 2020 (Avaliador B) Avaliado em 7 de junho de 2020 (Avaliador B)

Aceito em 2 de junho de 2021

\section{Introdução}

A saúde do trabalhador sempre esteve relacionada com as condições de trabalho fornecidas pelo empregador. Ocorre que a sanidade laboral, para além das condições físicas - instalações, uso de Equipamento de Proteção Individual (EPI) etc. -, pode estar relacionada à jornada de trabalho, seja no tocante à forma como a jornada de trabalho ocorre, ou mesmo em função do tempo empregado no desempenho da atividade laboral.

Note-se que o tema da saúde do trabalhador possui grande relevância, tanto que figura no rol dos direitos fundamentais sociais esculpidos no art. $7^{\circ}$ da Constituição Federal, existindo menção expressa no tocante à duração do trabalho nos incisos XIII, ${ }^{4} \mathrm{XIV},{ }^{5} \mathrm{XV}^{6}$ e XVI. ${ }^{7}$

Nos dias atuais a questão ganha especial pertinência considerando o movimento de grande precarização das relações de trabalho que surge em função da crise econômica que se arrasta há alguns anos. Tanto é assim que, segundo o IBGE ([201-b]), no $4^{\circ}$ trimestre de 2017 o número de desocupados no Brasil foi de 12,3 milhões de pessoas. Diante do aumento do desemprego, da disseminação da flexibilidade e da implementação do salário por mérito, uma das consequências acaba sendo a ocorrência de trabalho com maior intensidade.

Nesse contexto, adotando a premissa estabelecida pela Constituição Federal de que a proteção da jornada de trabalho é uma forma de proteção da saúde do trabalhador, busca-se analisar a (in)efetividade dos mecanismos disponíveis para a proteção do trabalhador contra o excesso de horas de trabalho no Brasil.

Para tanto, a presente pesquisa inicia por uma análise do impacto do trabalho em sobrejornada na saúde dos trabalhadores, especificamente na questão da exaustão do trabalho que, em situações extremas, pode causar a morte repentina ou dar causa ao suicídio. Isto será feito em perspectiva comparada, tomando como base o Japão e outros países asiáticos, tais como China,

\footnotetext{
4 "Art. $7^{\circ}[\ldots]$ XIII - duração do trabalho normal não superior a oito horas diárias e quarenta e quatro semanais, facultada a compensação de horários e a redução da jornada, mediante acordo ou convenção coletiva de trabalho;"

5 "Art. $7^{\circ}[\ldots]$ XIV - jornada de seis horas para o trabalho realizado em turnos ininterruptos de revezamento, salvo negociação coletiva;"

6 "Art. $7^{\circ}[\ldots]$ XV - repouso semanal remunerado, preferencialmente aos domingos;"

7 "Art. $7^{\circ}[\ldots]$ XVI - remuneração do serviço extraordinário superior, no mínimo, em cinqüenta por cento à do normal;"
} 
Coréia do Sul e Taiwan, haja vista concentrarem a maior incidência de casos de morte por excesso de trabalho (karoshi e karojisatsu). Portanto, em tais países se encontra o maior e mais profundo referencial teórico e estatístico disponível a respeito do tema.

Em seguida será analisado o excesso de horas de trabalho no Brasil, também sob a perspectiva dos danos por ele causados - inclusive com incidência de óbito (birôla) -, o que será feito com base na análise de casos concretos e dados estatísticos locais para, então, adentrar a análise dos mecanismos normativos disponíveis para tutelar a proteção jurídica contra esta prática ilícita, com especial destaque para a atuação do Ministério do Trabalho e do Ministério Público do Trabalho, sem deixar de lado a atuação da sociedade civil organizada, dos sindicatos e do próprio trabalhador submetido a tais condições.

Visando atingir o objetivo proposto neste estudo foi empregado o método históricocrítico em pesquisa num primeiro momento quantitativa e descritiva - vez que à partir dos dados quantitativos disponíveis descreve o problema no Japão e no Brasil - e, num segundo, qualitativa e aplicada - pois analisa qualitativamente os mecanismos existentes e apresenta resultados orientados à implementação nos casos concretos. Adotou-se os procedimentos bibliográfico e normativo, pois amparado por referências teóricas e normativas publicadas em meio escrito e eletrônico.

\section{Estudo comparado: o caso japonês}

\subsection{0 sistema de trabalho no Japão}

A flexibilização da forma de produção advinda do modelo japonês de gestão trouxe significativas modificações na forma com que o trabalho se desenvolveu no mundo (SILVA et al., 2006, p. 81).

O referido modelo, onde são expressões comuns o Círculo de Controles de Qualidade - CCQs, Gestão Participativa e Qualidade Total, foi exportado para grande parte dos países industrializados (HIRATA; ZARIFIAN, 1991, p. 174).

Um dos modelos de produção mais famosos do Japão, o toyotista, tem como característica um enxugamento do processo produtivo, visando o atendimento da demanda que se apresenta no momento (ANTUNES, 1953, p. 34).

Este modelo rompe com o fordismo e faz com que a vida do empregado seja mais intensa, pois o seu objetivo é reduzir desperdícios, evitando, dessa forma, que em momentos de crise o estoque acumulado em tempos de grande demanda não se perca, ou seja, a produção é realizada para as necessidades daquele momento (COSTA; ROSSO, 2010, p. 374).

Ocorre um melhor aproveitamento do tempo da empresa garantido pelo just in time e pela polivalência dos operadores - ou seja, a possibilidade de uma mesma pessoa operar várias máquinas (ANTUNES, 1953, p. 34). 
Este método de produção trouxe ao Japão um impulsionamento econômico bastante robusto, considerando que sua taxa de crescimento econômico superou $10 \%$ desde o pós-guerra até o início da década de 70, além de promover o reconhecimento mundial sobre a qualidade dos produtos e da gestão japonesa (FRANCO, 2002, p. 146).

Houve, portanto, um grande interesse no mundo empresarial como um todo em importar este sistema de produção (ANTUNES, 1953, p. 34), pois correspondia um símbolo de eficiência e modernidade do capitalismo (FRANCO, 2002, p. 145).

Como consequências deste modelo produtivo há o emprego de menor número de trabalhadores com a prática regular de horas extras - a ponto de um operário da Toyota trabalhar 2.300 horas, em média, por ano -, além da ocorrência da contratação de empregados temporários (ANTUNES, 1953, p. 36).

A diminuição dos custos da produção faz com que a atividade laboral seja mais intensa, com sobrecarga daqueles que mantém contratados permanentes, sendo imposta como condição de trabalho pela empresa, de forma explícita ou implícita, a prestação de horas extras (MARTINS, 2016, p. 110), suprimindo, assim, os "tempos mortos" (ROSSO, 1996, p. 57-58).

A forma da gerência do trabalho, nestas condições, resulta em um empregado mais engajado aos fins empresariais, fazendo com que se busque sempre melhores resultados, gerando, assim, a submissão do trabalhador a um trabalho extenuante e exaustivo, causando danos à sua saúde física e mental (MARTINS, 2016, p. 110).

A quantidade excessiva de horas trabalhadas contribui, portanto, para as más condições do trabalho, afetando de forma importante a sua saúde, a de sua família e sua vida social (LEE; McCAN; MESSENGER, 2009, p. 7).

\subsection{0 karoshi como fenômeno laboral}

Casos como o do Sr. Kanameda, que morreu de ataque cardíaco aos 34 anos, enquanto trabalhava 110 horas por semana em uma empresa de processamento de salgadinhos, da senhora Iwata, que morreu de um ataque de asma aos 23 anos, quando trabalhava em um grande banco onde se ativava por mais de 50 horas ilegais por mês e do senhor Yagi, que trabalhava por mais 70 horas por semana em um agência de publicidade, morreu de ataque cardíaco com 43 anos de idade tornaram-se comuns em países como o Japão (TOTSUKA; UEYANAGI, 1991, p. 1).

Histórias como essas possuem um mesmo enredo: jovens japoneses, com uma jornada de trabalho intensa e extrema, sem descansos ou pausas, e sua consequente morte.

Observando esse fenômeno, ou seja, a grande quantidade de horas de trabalho e mortes

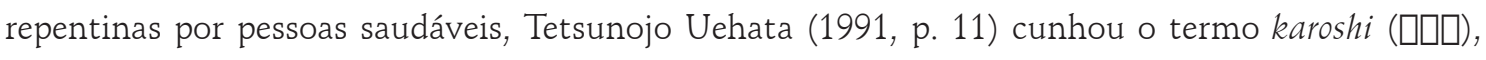
juntando os termos karo (excesso de trabalho) e shi (morte) para representar a morte por exaustão. 
Uehata (1991, p. 20) afirma ainda que o karoshi tornou-se conhecido durante o período da primeira crise do petróleo em 1974, apesar de Nishyama e Johnson (1997, p. 625) apontar que o primeiro caso relatado ocorreu em 1969 com a morte devido a um acidente vascular cerebral de um trabalhador de 29 anos de idade no departamento de expedição do maior jornal japonês.

A definição de karoshi é feita por Uehata (1991, p. 11) como condições de trabalho psicologicamente doentias que perturbam a vida normal do trabalhador, ocasionando um acúmulo de fadiga no corpo, aliado a agravamento da pressão arterial elevada e endurecimento das artérias resultando em um colapso fatal.

A morte por excesso de trabalho (karoshi) não se limita somente à morte por doença cardiovascular, apesar de ser a mais comum. No entanto, existe karoshi quando o empregado também é vítima de mortes decorrentes de um tratamento médico tardio, considerando a falta de tempo para ir a uma consulta médica e até mesmo nos suicídios atribuídos ao excesso de trabalho, tendo sido dado a este fato o nome de karojisatsu (NISHIYAMA; JOHNSON, 1997, p. 629).

Neste sentido, incluem-se também como karoshi as mortes ligadas ao coma diabético, úlcera péptica, asma brônquica e ruptura da veia esofágica relacionada ao mau funcionamento do fígado quando relacionadas ao excesso de trabalho (NISHIYAMA; JOHNSON, 1997, p. 629).

Apesar das horas de trabalho no mundo após a II Guerra Mundial terem diminuído, no Japão o número de homens que trabalham mais de 3.120 horas por ano, ou seja, mais de 60 horas em uma semana aumentou desde 1975 (NISHIYAMA; JOHNSON, 1997, p. 631).

Estima-se que cerca de 3 milhões de trabalhadores, o equivalente a 15\% da força masculina de trabalho, se ative por mais de 3.120 horas por ano, o que significa mais de 60 horas por semana. Em 1988 este número foi de 7 milhões de trabalhadores masculinos, ou 24\% da força de trabalho (NISHIYAMA; JOHNSON, 1997, p. 631).

Em 2004 a Organização Internacional do Trabalho - OIT apontou que o Japão tem a maior proporção de empregados que trabalham mais de 50 horas por semana $(28,1 \%)$, enquanto na maioria países da União Europeia ela é de 10\% (HIDA, 2008).

Isso demonstra que o trabalhador japonês possui uma jornada de trabalho maior do que a de um trabalhador de qualquer outro país industrializado (NISHIYAMA; JOHNSON, 1997, p. 631). Uma comparação realizada em 1987 no Japão indica que a média de horas trabalhadas anuais era de 2.168, enquanto que nos EUA era de 1.949, na Inglaterra 1.947, na França de 1.645 e na Alemanha de 1.642 (MORIOKA, 2002, p. 146).

Em uma pesquisa publicada em 2006 sobre o trabalho médico no Japão foi constatado que, em um universo de 5.983 médicos e 175 hospitais, 3.388 trabalhadores se ativavam por 66,4 horas por semana (JAPÃO, [200-]).

Ainda no Japão, a grande quantidade de horas extras advém da necessidade de um incremento da renda mensal do trabalhador, pois apesar de haver um limite legal de 40 horas semanais (art. 32 da Lei ${ }^{\circ}$ 49, de 7 abril de 1947), não existe um limite de horas extras. Dessa forma, 
o trabalhador que se ativa por mais de 8 horas recebe um adicional de $25 \%$ e aquele que passa de 12 horas de trabalho recebe um adicional de 50\% (ARAÚJO, 2006, p. 72).

Ocorre ainda o pagamento de um adicional de $25 \%$ a $50 \%$ sobre as horas trabalhadas em dias de folga, salvo nos casos em que o empregado tenha excedido 60 horas de trabalho, quando o adicional deve ser de, no mínimo, 50\% (art. 37 do Ato nº 49 de 07 de abril de 1947 (lei do trabalho japonesa) (JAPÃO, 1947).

Tais números fazem com que o sustento da família do trabalhador seja dependente do salário acrescido das horas extras (NISHIYAMA; JOHNSON, 1997, p. 630).

O pagamento do salário é correspondente ao período de efetivo trabalho, pois o art. 32 da lei trabalhista japonesa prevê que os descansos serão excluídos da jornada de trabalho.

Ademais, diante de uma linha de produção, o trabalhador que não prestar horas extras sobrecarregará o outro, pois não haverá reposição, ou seja, este não será bem visto perante a empresa e seus colegas de trabalho (ARAÚJO, 2006, p. 72).

A cultura japonesa, de certa forma, contribui para a ocorrência de excesso de trabalho considerando o alto grau de comprometimento com as suas atividades, com a empresa e com os demais colegas. Atribuiu-se um termo japonês a este fato, o ganbaru, que significa suportar, não desistir, ser paciente e persistir em uma tarefa mesmo que difícil e estressante pelo tempo necessário até atingir o sucesso (MEEK, 1999, p. 29).

Existe ainda trabalho em horas extras sem remuneração, situações estas em que o empregado doa à empresa a sua mão de obra, como um trabalho voluntário (CARREIRO, 2007, p. 131). Quanto a este sistema, Franco (2002, p. 154) refere-se como o instituto do service overtime, isto é, doação de trabalho sem registro do tempo despendido, com ocorrência especialmente em trabalhadores na área financeira e em escritórios.

Além disso não se contabiliza também o tempo de trabalho que o empregado leva para a sua casa, o chamado furoshiki overtime (FRANCO, 2002, p. 154).

A gestão das empresas também influencia a forma de trabalho, pois o empresário japonês não vê com bons olhos o empregado que não labora durante várias horas por dia, não faz horas extras e sempre usufrui férias remuneradas, o que impede a progressão na carreira ou até mesmo acarreta a sua demissão (FRANCO, 2002, p. 156).

Aliado a isso tem-se as filosofias do just in time e da qualidade total com práticas chamadas de zeros: zero erro, prazo zero e quebra zero, impondo uma qualidade e uma eficiência que impacta na saúde do trabalhador (HIRATA; ZARIFIAN, 1991, p. 174).

Nishiyama e Johnson (1997, p. 632), apresentando essa atmosfera idealista de comportamento, citam o anúncio feito por uma empresa farmacêutica na televisão japonesa para uma nova bebida: "Você pode lutar por sua corporação durante 24 horas?"

A presença de realização de muitas horas de trabalho não é um fenômeno exclusivo japonês. Existem relatos da sua ocorrência na Coréia do Sul, em Taiwan (CHANG; LIN, 2019, p. 
279; PARK; KIM; CHENG, 2011, p. 17) e na China (XIAO et al., 2019, p. 357), e embora a lei sugira um uma jornada máxima de 44 horas semanais ela é raramente aplicada (LI et al., 2014, p. 661).

\subsection{Excesso de trabalho mata}

Em estudo realizado com vendedores japoneses de uma empresa fabricante de máquinas, as longas jornadas elevaram o nível de pressão arterial e diminuição do colesterol Total (IWSASAKI et al., 1998, p. 367).

No ano de 1990, um estudo de caso-controle envolvendo 195 japoneses com idade entre 30 e 69 anos com quadro de infarto no miocárdio concluiu que o aumento da jornada média de trabalho no ano anterior contribuiu significativamente para a ocorrência do infarto (SOKEJIMA; KAGAMIMORI, 1991, p. 779).

Outro estudo caso-controle com 260 homens com idade de 40 a 79 anos internados em hospitais durante os anos de 1996 a 1998 concluiu que há um aumento do risco de infarto do miocárdio quando o trabalho semanal for igual ou superior a 61 horas em comparação com aqueles submetidos a menos de 40 horas de trabalho (LIU; TANAKA, 2002, p. 447). Neste mesmo estudo concluiu-se também que a ausência de sono ou um período inferior a 5 horas de sono também estão associados a um aumento do risco de infarto no miocárdio (LIU; TANAKA, 2002, p. 451).

Diante disso Landsbergis (2004, p. 1748) concluiu que o excesso de horas de trabalho (superiores a 55-60 horas por semana) está relacionado ao infarto do miocárdio e aumento da pressão arterial.

Não obstante tais constatações, um estudo realizado em Tóquio entrevistou 500 executivos de uma grande companhia e o relatório demonstrou que $46 \%$ dos entrevistados possuíam quadro de ansiedade sobre karoshi, sendo que $20 \%$ deles tinha medo de que eles próprios viessem a ser acometidos (NISHIYAMA; JOHNSON, 1997, p. 625-626).

Pode-se notar, portanto, que o termo karoshi não representa somente um termo médico, mas sim sócio-médico, que se refere a fatalidades ou associações decorrente de longas horas e uma sobrecarga de trabalho (ORGANIZAÇÃO INTERNACIONAL DO TRABALHO, 2013).

Diante dos inúmeros problemas decorrentes do karoshi no Japão, um grupo de voluntários formados por médicos e advogados criou em 1988 uma linha direta (Karoshi Hot Line) para oferecer conselhos sobre pedidos de indenização para casos de estresse decorrente do trabalho e em um prazo de 2 anos foram recebidas 1.800 consultas (UEHATA apud HERBIG; PALUMBO, 1994, p. 23).

Franco (2002, p. 147) aponta que inicialmente este serviço atendia somente os 7 maiores centros urbanos japoneses, tendo recebido no primeiro dia do programa 135 consultas, sendo que no primeiro ano 309 casos de karoshi foram registrados.

Existe um sítio da internet com divulgação de dados, estudos e informações (http:// karoshi.jp/syukei.html). O número de telefone está à disposição do trabalhador ou da família para o 
atendimento sobre dúvidas, aconselhamento ou de denúncias de karoshi e karojisatsu, tendo recebido 11.172 consultas entre 18 de junho de 1988 a 20 de junho de 2015.

Das consultas realizadas $55 \%$ são de viúvas, pois seus maridos faleceram por infarto, falência cardíaca ou acidente vascular cerebral, e 20\% são de pessoas que procuram medidas de prevenção para evitar a fadiga e a morte pelo excesso de trabalho (FRANCO, 2002, p. 147).

O Estado japonês, por meio do Ministério do Trabalho, paga compensações financeiras para a família do trabalhador morto em decorrência do excesso de trabalho, desde que seja comprovado que o falecido tenha laborado por pelo menos 16 horas por dia, durante 7 dias consecutivos, inclusive durante as 24 horas anteriores ao falecimento. No entanto, caso o empregado tenha laborado por 2.500 horas por ano, mas não cumpra esses requisitos, sua família não receberá a indenização (CARREIRO, 2007, p. 137).

A empresa também é responsabilizada em caso de morte do empregado decorrente de excesso de trabalho e a família recebe indenização equivalente ao ganho de 1.000 dias de salário (art. 79 da lei trabalhista), além do valor correspondente a 60 salários para despesas com funeral (art. 80 da lei trabalhista).

O Gráfico 1 demonstra o número de casos onde se aprovou o pagamento da compensação pelo governo japonês para os casos de karoshi e karojisatsu em um período de 14 anos (1997 a 2011). Pode-se notar que nos casos de karoshi houve um aumento de 47 para 121 e de karojisatsu de 2 para 66 (ORGANIZAÇÃO INTERNACIONAL DO TRABALHO, 2013).

Gráfico 1 - Casos de pagamento da compensação pelo governo japonês para os casos de karoshi e karojisatsu em 14 anos (1997 a 2011$)$

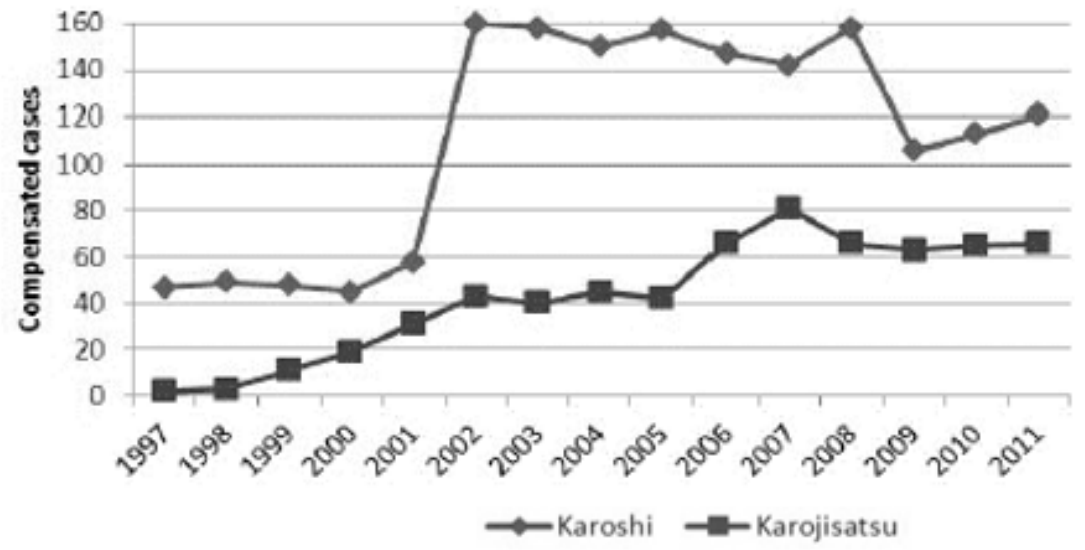

Fonte: Organização Internacional do Trabalho (2013).

No Gráfico 2, Yang e Yang (2015, p. 349) comparam as compensações financeiras pagas nos casos de karoshi decorrentes de doenças cardiovasculares no Japão, na Coreia do Sul e Taiwan, além da compensação paga para os casos de morte súbita causada por doença no trabalho na China: 
Gráfico 2 - Comparativo de compensações financeiras pagas no Japão, na Coreia do Sul e em Taiwan nos casos de karoshi decorrentes de doenças cardiovasculares (1996 a 2012)

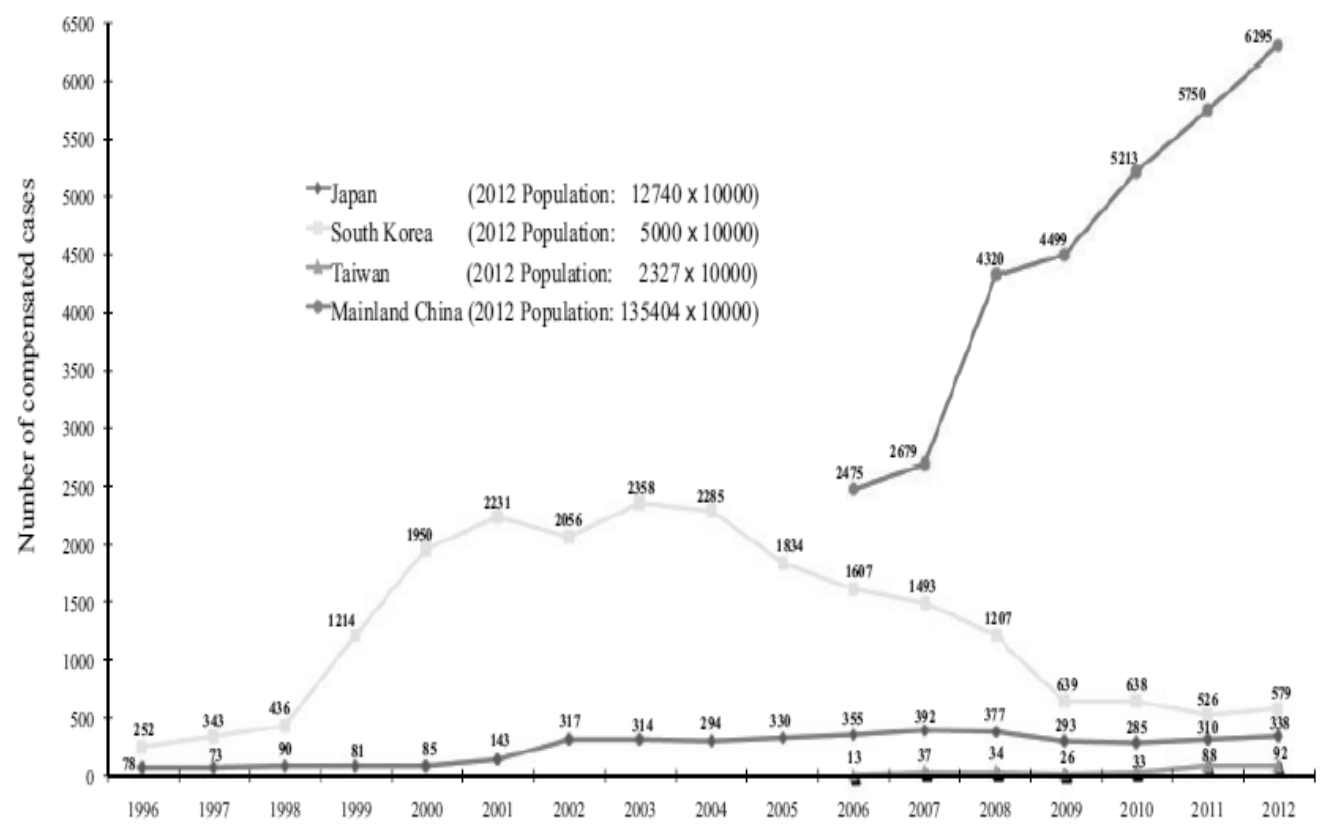

Fonte: Yang e Yang (2015).

Pelos dados divulgados pelo Ministério da Saúde, Trabalho e Bem Estar japonês em 2016 o número de reclamações referentes a morte de trabalhadores decorrentes de doença cerebral ou cardíaca foi de 825, um aumento de 30 mortes em relação ao ano anterior. A partir deste número houve a decisão de pagar as compensações financeiras pelo dano em 260 casos, o que correspondeu a um aumento de 9 em relação ao ano de 2015 (JAPÃO, 2018).

A presença do efeito karoshi está tão enraizada na cultura japonesa que nos meses de novembro o Japão promove o mês da consciência e da prevenção da morte por excesso de trabalho. Inclusive, ocorreu em 2017 a organização de um Simpósio para a promoção de medidas de prevenção à morte por excesso de trabalho e eliminação do trabalho excessivo, evento este que conta com um sítio na internet para divulgação. Neste evento, chama a atenção o texto de início que apresenta a motivação do simpósio:

Para que os diversos recursos humanos trabalhem com longevidade e por um longo tempo em uma empresa é importante primeiro eliminar o excesso de trabalho em cada empresa. Para tanto, precisamos empreender voluntariamente iniciativas como "redução do tempo de trabalho prolongado", "gestão do tempo de trabalho" e "medidas para prevenir problemas de saúde". (JAPÃO, 2017).

Diante do quadro grave da prática de excessivas horas extras pelos trabalhadores japoneses foi formada uma estrutura para enfrentar o problema, acolhendo o trabalhador, seus familiares e estabelecendo punição para o empregador. 


\section{0 excesso de trabalho no Brasil}

\subsection{0 histórico brasileiro}

A morte ou as doenças incapacitantes decorrentes do excesso de trabalho já são bastante conhecidas no Japão e em alguns países asiáticos, contando até mesmo com uma estrutura legal e financeira aliada ao movimento de conscientização do problema.

No Brasil, entretanto, não se nota qualquer movimento neste sentido, o que não significa que ele não ocorra aqui.

No Anuário Estatístico de Acidentes do Trabalho do Brasil, publicado pelo Ministério da Previdência Social no ano de 2015, existe a indicação de 192 mortes de trabalhadores por causas desconhecidas (BRASIL, 2015, p. 534).

Silva et al. (2006, p. 74) apontam que, nos anos de 2004 e 2005, no trabalho em canaviais para empresas do setor sucroalcooleiro do Estado de São Paulo foram registradas 13 mortes em razão do excesso de esforço. Os trabalhadores relataram dores de cabeça, fortes cãibras, desmaios e parada cardiorrespiratória.

A Relatoria Nacional para o Direito Humano do Trabalho da Procuradoria Geral da República na Missão na Região de Ribeirão Preto (COSTA; NEVES, 2006, p. 81-82), em visita a duas frentes de trabalho da Usina Maringá, no município de Rincão/SP, e ao alojamento Jibóia, mantido pela Usina Santa Helena, do Grupo COSAN, indicou a existência de pagamento por produção de R \$ 0,11 a R \$ 0,22 por metro quadrado, o que fomentava uma produção elevada. Além disso, constatou-se que quando os trabalhadores se ausentavam do trabalho precisavam repor a produção do dia perdido.

No alojamento Jiboia foi constatado ainda que o início da jornada de trabalho ocorria às 5h30, sem horário para encerrar e também sem pausas para descanso. Já no alojamento da Usina Maringá os trabalhadores iniciavam o trabalho entre 5 h e 6 h com finalização às 15 h50 para então realizarem a coleta de bituca - pedaços de cana-de-açúcar não aproveitáveis para a fabricação dos produtos derivados da cana-de-açúcar.

No mesmo plano a Pastoral do Migrante do Município de Guariba, Estado de São Paulo, aponta que até o ano de 2009 ocorreram 21 mortes relacionadas ao corte de cana (FACIOLI; PERES apud ROSA; NAVARRO, 2014, p. 144).

Note-se que no setor rural a exaustão decorrente do trabalho é tão comum que os trabalhadores já possuem uma nomenclatura designativa da sua ocorrência: birôla (SILVA, 2006, p. 76). Trata-se do equivalente brasileiro do termo karoshi.

Tal como no caso japonês, o trabalhador possui morte súbita após a ocorrência de cãibras, desmaios e posterior parada cardiorrespiratória ou acidente vascular cerebral devido o esforço excessivo no trabalho (SILVA, 2006, p. 75). 
De outro plano, no setor da saúde enfermeiros e auxiliares de enfermagem laboram em jornadas duplas ou triplas, fazendo com que as horas de trabalho sejam elevadas. Dalri (2013, p. 87), em estudo realizado na Unidade de Emergência do Hospital das Clínicas da Faculdade de Medicina de Ribeirão Preto, constatou que, numa população de 95 enfermeiros, 29 deles (30,5\%) exercem suas atividades por até 36 horas semanais, 49 (51,6\%) laboravam de 37 a 57 horas por semana e 17 $(17,9 \%)$ entre 58 e 78 horas semanais.

Porém, casos de óbito também ocorrem no Brasil. Tanto é assim que no ano de 2006 o Ministério Público do Trabalho de Minas Gerais ajuizou Ação Civil Pública em face da empresa Metalsider Ltda. requerendo a aplicação de medidas judiciais para a garantia da segurança e saúde do trabalho em razão da morte de um trabalhador daquela empresa, cuja causa mortis apontada foi a exaustão decorrente do excesso de jornada de trabalho, além da ausência de descanso semanal. Frise-se que o julgamento foi de procedência, determinando à empresa que respeitasse a limitação da jornada legal e os períodos de descanso (CARREIRO, 2007, p. 133).

Não se deve perder de vista ainda que uma das características do trabalho análogo à situação de escravo é justamente a jornada exaustiva, ocorrendo de forma não rara um trabalho com duração de 12 horas (SILVA, 2010, p. 157).

Nesse sentido, o reconhecimento formal do trabalho escravo no Brasil, perante a comunidade internacional, ocorreu em 1995 e até o ano de 2010 foram resgatados 38 mil trabalhadores. Ademais, estima-se que apenas 50\% das denúncias são apuradas e, portanto, o número de trabalhadores submetidos à péssimas condições de trabalho é ainda maior do que o efetivamente flagrado (BRASIL, 2011).

Costa et al. (2014, p. 179) ressalvam que as informações censitárias e provenientes da Pesquisa Nacional por Amostra de Domicílios (PNADs) fazem referência somente ao principal trabalho das pessoas. Porém, deve-se ter em mente que no Brasil 3,7 milhões de pessoas possuem dois ou mais trabalhos. Contudo, o número de pessoas submetidas a jornada excessiva em 2010 era de 13,3 milhões, o que equivale a 15,4\% da população economicamente ativa do país.

Diante dos dados estatísticos e dos casos concretos apresentados pode-se constatar que o excesso de trabalho não é algo tão distante da realidade brasileira. $O$ trabalhador brasileiro pode não ter o perfil e/ou a cultura laboral de um trabalhador japonês. Contudo, ante às informações coletadas, é inegável que em muitas situações o número de horas trabalhadas excede o permissivo legal, o que coloca em risco a saúde do trabalhador.

\subsection{Os mecanismos de proteção contra o excesso de trabalho}

A Consolidação das Leis do Trabalho (CLT) (Decreto-Lei no 5452/43) em seu art. 58 prevê que a duração normal do trabalho não poderá exceder 8 horas diárias. Porém, em razão da 
Lei $n^{\circ} 605 / 49$ dispor sobre o direito do empregado a um dia de descanso por semana trabalhada, era admitida uma a jornada semanal limite de 48 horas.

O limite de 44 horas semanais atualmente vigente foi trazido pelo inciso XIII do art. $7^{\circ}$ da Constituição Federal de 1988, o qual inaugurou um novo limite de jornada de trabalho, aplicável tanto para trabalhadores urbanos quanto rurais.

Contudo, existem limites de jornada de trabalho diferenciados, os quais são estabelecidos conforme a necessidade e de acordo com o tipo de profissão exercida. Vide, v.g., que os jornalistas (art. 303 da CLT) e os músicos (art. 41 da Lei n 3.857/60) possuem jornada diária de 5 horas (art. 303 da CLT). Já os terapeutas ocupacionais tem como limite a jornada semanal de 30 horas (art. $1^{\circ}$ da Lei 8.856/94).

No entanto, considerando o estágio atual de desenvolvimento tecnológico e os consequentes ganhos em produtividade, há uma tendência mundial em estabelecer-se uma jornada semanal de 40 horas (LEE; MCCAN; MESSENGER, 2009, p. 2).

É preciso lembrar que, conforme demonstrado anteriormente, a duração do trabalho está ligada umbilicalmente com a saúde do trabalhador, vez que o descanso é um componente de restabelecimento da energia física e mental, pois permite a realização de higiene mental nos momentos de lazer e de convívio em comunidade durante o tempo livre (CARDOSO, 2013, p. 357).

Todavia, os dados divulgados pela Pesquisa Nacional por Amostra de Domicílios (PNAD 2014-2015) (IBGE, [201-a]) apontam que no ano de 2014 estava em 26,4\% o percentual de brasileiros que trabalhavam mais de 45 horas por semana - em que pese tenha caído para 24\% em 2015.

Analisando os dados estatísticos referentes à jornada de trabalho dos brasileiros, Marcelo Perrucci (2017) constatou que, por ano, o brasileiro trabalha 149 horas a mais do que um trabalhador dos países membros da Organização para a Cooperação e Desenvolvimento Econômico (OCDE).

Visando a proteção do trabalhador no tocante ao respeito ao limite estabelecido para a jornada de trabalho no Brasil existe uma estrutura de fiscalização administrativa realizada pelo Ministério do Trabalho, além da atuação do Ministério Público do Trabalho. Este último, por seu turno, pode valer-se de mecanismos de composição extrajudicial, como o Termo de Ajustamento de Conduta, além do recurso à via judicial por meio do ajuizamento da Ação Civil Pública em face do empregador.

Como bem pontuado por Cardoso e Lage (2005, p. 453), a efetividade da legislação trabalhista depende de interação entre o montante das sanções e a probabilidade do empregador ser apanhado burlando a lei. Daí, portanto, a necessidade da atuação fiscalizatória do Ministério do Trabalho e do Ministério Público do Trabalho.

Para tanto o art. 75 da Consolidação das Leis do Trabalho (CLT) prevê a aplicação de multa ao empregador que não cumprir as disposições acerca da duração da jornada de trabalho, sendo esta fiscalização exercida pelos fiscais que atuam nas Superintendências Regionais do Trabalho e Emprego. 
Já o Ministério Público do Trabalho pode utilizar o Termo de Ajustamento de Conduta como meio de transação extrajudicial visando a celebração do compromisso de cessação da violação a interesses difusos, coletivos ou individuais homogêneos e, caso não seja cumprido, converte-se em título executivo extrajudicial para fins de execução. Portanto, o órgão ministerial pode propor ao empregador a assinatura de um Termo de Ajustamento de Conduta para que a prestação de horas extras não seja habitual, sob pena de aplicação de sanção em caso de negativa.

Frise-se que, em se tratando de trabalho com excessivas horas extras, a lesão praticada pelo empregador será considerada como violadora de direito individual homogêneo. Daí surgiu a possibilidade para o Ministério Público do Trabalho de propor a celebração de Termo de Ajustamento de Conduta ou até mesmo promover diretamente uma Ação Civil Pública, conforme previsto no art. 83, III da Lei Complementar nº 75/93.

Caso opte pela ação o órgão ministerial poderá pleitear o pagamento de indenização por dano material, compensação financeira por dano moral ou ainda obrigação de fazer ou não fazer.

Ademais, é preciso frisar que a legitimidade para a propositura da Ação Civil Pública não está adstrita ao Ministério Público, podendo também propo-la as associações comunitárias e/ou profissionais não-estatais, desde que demonstrem interesse legítimo na ação (DIAS, 2006). Referida informação é importante na medida em que o número de servidores disponíveis para o exercício da atividade fiscalizatória é restrito tanto no âmbito no Ministério do Trabalho (RIBEIRO, 2013) quanto do Ministério Público do Trabalho (BRASIL, 2006).

Todavia, é preciso frisar que o trabalhador ou o sindicato da categoria possuem legitimidade para ajuizar ação em face do seu empregador buscando a concessão de tutela inibitória para que cessem as prestações de horas excessivas, sem prejuízo do pagamento de horas extras, além das indenizações próprias para fins de reparação civil.

\section{Conclusão}

A partir da análise realizada é possível constatar que os dados estatísticos obtidos em relação ao Japão e países asiáticos como Coréia do Sul, China e Taiwan demonstram que existe uma relação entre jornada de trabalho e saúde do trabalhador. Mais do que isso, restou comprovado que o excesso de trabalho pode levar a óbito, seja por exaustão (karoshi) ou pela indução depressiva ao suicídio (karojisatsu).

Foi possível constatar também, com base nos dados estatísticos e nos casos concretos ocorridos no Brasil, que o excesso de horas de trabalho é uma realidade brasileira, sobretudo no meio rural.

Isso posto, cruzando as conclusões obtidas na análise do caso japonês e dos demais países asiáticos já citados, com aquelas encontradas no tocante a jornada excessiva de trabalho no Brasil é 
possível confirmar que também aqui o excesso de horas de trabalho enseja casos de óbito, seja por exaustão (birôla) ou pela indução depressiva ao suicídio.

Uma vez constatada a relação existente entre saúde do trabalhador e excesso de horas de trabalho - inclusive com potencial de óbito - foi possível identificar que, de modo a garantir a proteção da jornada de trabalho prevista constitucionalmente, foram criados mecanismos coercitivos aptos a coibir ou fazer interromper administrativa ou judicialmente a ocorrência desta espécie de ilícito. Porém, frise-se que, ao lado dos atores estatais, existem medidas judiciais (as administrativas são exclusivamente estatais) disponíveis para a atuação da sociedade civil organizada, dos sindicatos de categoria profissional e do próprio trabalhador sujeito a tais condições.

Em função disso é possível concluir que o aparato normativo existente - ao contrário do que ocorre no Japão e outros países asiáticos - é suficiente para coibir ou mesmo fazer interromper a violação ao limite de horas de trabalho estabelecido na Constituição Federal, seja pela via administrativa ou judicial. Portanto, eventual descumprimento que impacte na saúde do trabalhador - sem com isso eximir a responsabilidade do empregador - somente será possível ante (i) a falta de fiscalização pelo Estado, seja pelo número insuficiente de agentes ou mesmo por má gestão, (ii) o baixo grau de engajamento da sociedade civil, (iii) a atuação insuficiente do sindicato da categoria ou (iv) a passividade submissa do trabalhador, em virtude do desconhecimento da lei ou da necessidade econômica. Afinal, existem mecanismos normativos eficientes disponíveis para todos estes atores.

Em síntese, conclui-se que, diferentemente do Japão e demais países asiáticos, o aparato normativo brasileiro é suficiente para a proteção da saúde do trabalhador frente ao excesso de horas de trabalho. Porém, a ocorrência de violações concretas não se deve à (in)efetividade do marco legal, mas sim a omissão dos atores envolvidos.

\section{Referências}

ANTUNES, Ricardo. Adeus ao Trabalho? Ensaio sobre as metamorfoses e a centralidade do mundo do trabalho. 11. ed. São Paulo: Cortez, 1953.

ARAÚJO, João Paulo Santos. O homem cordial e o toyotismo: a dificuldade de inserção dos dekasseguis brasileiros. 2006. Monografia (Bacharelado em Relações Internacionais ) - Centro Universitário de Brasília, Brasília, DF, 2006.

BRASIL. Estimativas apontam número quatro ou cinco vezes maior de escravos. Revista Em Discussão, v. 2, n. 7, 2011. Disponível em: https://www.senado.gov.br/noticias/Jornal/emdiscussao/trabalho-escravo/mao-de-obra-escrava/estimativas-apontam-numero-quatro-ou-cinco-vezes-maior-de-escravos.aspx. Acesso em: 19 abr. 2018.

BRASIL. Ministério da Previdência Social. Anuário estatístico de acidentes do trabalho, v. 1, p. 1-1991, 2015. 
BRASIL. Ministério Público do Trabalho - PRT $7^{a}$ Região. Diagnóstico com procuradores expõe perfil do MPT. Brasília, DF: [s. n.], 2006. v. II. Disponível em: http://servicos.prt7.mpt.gov.br/noticias/2006/ novembro/21_11_06_diagnostico_procuradores_perfil_MPT.htm. Acesso em: 19 abr. 2018.

CARDOSO, Adalberto; LAGE, Telma. A inspeção do trabalho. Revista de Ciências Sociais, v. 48, n. 3 , p. 451-490, 2005.

CARDOSO, Ana Claudia Moreira. Organização e intensificação do tempo de trabalho. Soc. Estado, v. 28, n. 2, p. 351-374, 2013.

CARREIRO, Líbia Martins. Morte por excesso de trabalho (karoshi). Revista do Tribunal Regional do Trabalho da $3^{a}$ Região, v. 46, n. 76, p.131-141, 2007.

CHANG, Heng-Hao; LIN, Ro-Ting. Policy changes for preventing and recognizing overwork $\square$ related cardiovascular diseases in Taiwan: an overview. J Occup Health, v. 61, p. 278-287, 2019. DOI: https://doi.org/10.1002/1348-9585.12046.

COSTA, Cândida da et al. Intensidade e trabalho excessivo: exaustão, impactos na subjetividade e formas de resistência dos (as) trabalhadores (as). Revista de Políticas Públicas, v. 18, p. 177-187, 2014.

COSTA, Cândida da; NEVES, Ciani Sueli. Superexploração do Trabalho na Lavoura de Cana-de-Açúcar. In: RODRIGUES, Maria Elena (org.). Relatores nacionais em direitos economicos, sociais, culturais e ambientais. Informe 2005. Rio de Janeiro: Plataforma Brasileira de Direitos Humanos Econômicos, Sociais e Culturais. Relatores Nacionais em Direitos Econômicos, Sociais, Culturais e Ambientais, 2006. p. 79-87. Disponível em: http://pfdc.pgr.mpf.p.br/atuacao-e-conteudos-de-apoio/publicacoes/direitos-humanos/revista-relatorias.pdf. Acesso em: 16 abr. 2018.

COSTA, José Alves da; ROSSO, Sadi Dal. Mais trabalho! A intensificação do labor na sociedade contemporânea. Revista Sociedade e Estado, v. 25 n. 2, p. 371-375, 2010.

DALRI, Rita de Cássia de Marchi Barcellos. Carga horária de trabalho dos enfermeiros de emergência e sua relação com estresse e cortisol salivar. 2013. Tese (Doutorado) - Escola de Enfermagem de Ribeirão Preto, Universidade de São Paulo, Ribeirão Preto, 2013.

DIAS, Mônica Nazaré Picanço. Ação Civil Pública Como Instrumento de Defesa do Meio Ambiente do Trabalho. In: ENCONTRO NACIONAL DO CONPEDI, 15., 2006, Manaus. Anais [...] Manaus, 2006. Disponível em: http://www.publicadireito.com.br/conpedi/manaus/arquivos/anais/ manaus/transf_trabalho_monica_picanco_dias.pdf. Acesso em: 26 set. 2018.

FRANCO, Tânia. Karoshi: o trabalho entre a vida e a morte. Caderno CRH, n. 37, p. 141-161, 2002.

HERBIG, Paul A.; PALUMBO, Frederick A. "Karoshi": salaryman sudden death syndrome. Journal of Managerial Psychology, v. 9, n. 7, p. 11-16, 1994.

HIDA, Misako. The land of karoshi: the story that won the 2008 Media for labour rights prize. Genebra: Organização Internacional do Trabalho, 2008. Disponível em: http://ilsforjournalists.itcilo.org/en/media-for-labour-rights-journalistic-prize/ the-best-story-on-labour-rights-2008-ed./? searchterm=misako\%20hida. Acesso em: 15 abr. 2018.

HIRATA, Helena; ZARIFIAN, Philippe. Força e fragilidade do modelo japonês. Estudos Avançados, v. 5, n. 12, p. 173-185, 1991. Disponível em: http://www.scielo.br/scielo.php?script=sci_arttext\&pi$\mathrm{d}=$ S0103-40141991000200011\&lng=pt\&tlng=pt. Acesso em: 26 set. 2018. 
IBGE. Brasil em Sintese, Diretoria de Pesquisas, Coordenação de Trabalho e Rendimento, Pesquisa Nacional por Amostra de Domicílios 2014-2015. Brasília, DF: IBGE, [201-a]. Disponível em: https://brasilemsintese.ibge.gov.br/trabalho/horas-trabalhadas.html. Acesso em: 26 set. 2018.

IBGE. Pesquisa Nacional por Amostra de Domicílios Contínua Divulgação Especial Medidas de Subutilização da Força de Trabalho no Brasil, 2017. Brasília, DF: IBGE, [201-b]. Disponível em: ftp://ftp. ibge.gov.br/Trabalho_e_Rendimento/Pesquisa_Nacional_por_Amostra_de_Domicilios_continua/ Trimestral/Novos_Indicadores_Sobre_a_Forca_de_Trabalho/pnadc_201201_201704_trimestre_novos_indicadores.pdf. Acesso em: 26 mar. 2018.

IWSASAKI, Kenji et al. Effect of working hours on biological functions related to cardiovascular system among salesmen in a machinery manufacturing company. Industrial Health, n. 36, p. 361367, 1998.

JAPÃO. Lei no 49 de 7 april 7 de 1947. Disponível em: http://www.cas.go.jp/jp/seisaku/hourei/ data/LSA.pdf. Acesso em: 15 abr. 2018.

JAPÃO. Ministério da Saúde, Trabalho e Bem Estar. Disponível em: http://partner.lec-jp.com/ti/ overwork/. Acesso em: 5 abr. 2018.

JAPÃO. Ministério da Saúde, Trabalho e Bem Estar. Novembro é mês da iluminação para prevenir a morte do excesso de trabalho. [S. l.: s. n.], 2017. Disponível em: http://www.mhlw.go.jp/stf/houdou/0000177422.html. Acesso em: 5 abr. 2018.

JAPÃO. Pesquisa de status de trabalho do médico sobre a oferta e a demanda do médico (para hospitais): resultados provisórios. [S. l.: s. n.], [200-]. Disponível em: http://www.mhlw.go.jp/shingi/2006/02/ s0208-12b.html. Acesso em: 6 abr. 2018.

LANDSBERGIS, Paul. Long work hours, hypertension, and cardiovascular disease. Cadernos de Saúde Pública, v. 20, n. 6, p. 1746-1748, 2004.

LEE, Sangheon; MCCAN, Deirdre; MESSENGER, John Cowan. Duração do trabalho em todo o mundo: tendências de jornadas de trabalho, legislação e políticas numa perspectiva global comparada. Brasília, DF: OIT, 2009.

LI, Jian et al. Compensation for disease caused sudden death at work in China 2006-2012. Occupational and Environmental Medicine, v. 71, n. 9, 2014.

LIU, Ying.; TANAKA, Hiroshi. Overtime work, insufficient sleep, and risk of non-fatal acute myocardial infarction in Japanese men. Occupational and Environmental Medicine, v. 59, n. 7, p. 447-451, 2002 .

MARTINS, Marianne Lima. Na linha de frente: a intensificação do trabalho em bancos públicos e suas implicações sobre a saúde dos trabalhadores bancários. 2016 Dissertação (Mestrado em Sociologia) - Universidade de Brasília, Brasilia, DF, 2016.

MEEK, Christopher Bishop. Ganbatte: understanding the Japanese employee. Business horizons, v. 42, n. 1, p. 27-36, 1999. 
MORIOKA, Rika. Anti-karoshi activism in a corporate-centered society: medical, legal, and housewife activist collaborations in constructing death from overwork in Japan. 2008. Dissertação (Mestrado em Filosofia) - Universidade da California, San Diego, Estados Unidos da América, 2008. Disponível em: https://escholarship.org/uc/item/98s1c756. Acesso em 20 maiO 2018.

NISHIYAMA, Katsuo; JOHNSON, Jeffrey V. Karoshi - Death from overwork: occupational health consequences of Japanese production management. International Journal of Health Services, v. 27, n. 4, p. 625-641, 1997.

ORGANIZAÇÃO INTERNACIONAL DO TRABALHO. Case Study - Karoshi: death from overwork. Genebra: OIT, Apr. 2013. Disponível em: http://www.ilo.org/safework/info/publications/ WCMS_211571/lang--en/index.htm. Acesso em: 6 abr. 2018.

PARK, Jungsun; KIM, Yangho; CHENG, Yaween. A comparison of the recognition of overwork-related cardiovascular disease in Japan, Korea and Taiwan. Industrial Health, n. 50, n. 1, p. 17-23, 2011.

PERRUCCI, Marcelo. Cala boca e trabalhe. UNACON Sindical, Brasília, DF, mar. 2017. Disponível em: http://www.unacon.org.br/cno-4040/artigo-compara-jornada-de-trabalho-dos-paises-da-ocde-com-a-realidade-brasileira/. Acesso em: 26 set. 2018.

RIBEIRO, Luiz. Falta de auditores fiscais compromete ação do ministério no combate ao trabalho escravo. Jornal Estado de Minas, maio 2013. Disponível em: https://www.em.com.br/app/noticia/ economia/2013/05/19/internas_economia,390463/falta-de-auditores-fiscais-compromete-acao-do-ministerio-no-combate-ao-trabalho-escravo.shtml. Acesso em: 19 abr. 2018.

ROSA, Leandro Amorim; NAVARRO, Vera Lúcia. Trabalho e trabalhadores dos canaviais: perfil dos cortadores de cana da região de Ribeirão Preto (SP). Cadernos de Psicologia Social do Trabalho, v. 17, n. 1, p. 143-160, 2014.

ROSSO, Sadi Dal. A jornada de trabalho na sociedade. São Paulo: LTr, 1996.

SILVA, Marcelo Ribeiro. Trabalho análogo ao de escravo rural no Brasil do século XXI: novos contornos de um antigo problema. 2010. Dissertação (Mestrado) - Universidade Federal de Goiás, Goiânia, 2010 .

SILVA, Maria Aparecida de Moraes et al. Do karoshi no Japão, à birôla no Brasil: as faces do trabalho no capitalismo mundializado. Revista Nera, v. 8, n. 9, p. 74-108, 2006.

SOKEJIMA, Shigeru; KAGAMIMORI, Sadanobu. Working hours as a risk factor for acute myocardial infarction in Japan: case control study. BMJ, v. 317, p. 778-780, 1991.

TOTSUKA, Etsuro; UEYANAGI, Toshio. Prevention of death from overwork and remedies for its victims. [S. l.: s. n.], 1991. Disponível em: http://karoshi.jp/english/overwork1.html. Acesso em: 13 mar. 2018.

UEHATA, Tetsunojo. Karoshi due to occupational stress-related cardiovascular injuries among middle-aged workers in Japan. Science of labour, v. 67, n. 1 (Part II), p. 20-28, 1991. Disponível em: https://darch.isl.or.jp/il/cont/01/G0000002rouken/000/019/000019494.pdf. Acesso em: 6 set. 2020. 
XIAO, Ning et al. Karoshi May Be a Consequence of Overwork-Related Malignant Arrhythmia. Med Sci Monit., n. 25, p. 357-364, 2019. Disponível em: https://www.medscimonit.com/abstract/ index/idArt/911685. Acesso em: 6 set. 2020.

YANG, Zichu; YANG, Bo-Fan; LI, Jian. Perspectives on compensation and legislation of death due to work overload-karoshi. QJM: An International Journal of Medicine, v. 108, p. 349-350, 2015. 